\title{
O uso da autobiografia na educação de adultos: modos narrativos de valorização e legitimação da experiência profissional
}

ANTÓNIO CALHA

Instituto Politécnico de Portalegre, Portalegre, Portugal

RESUMO

As alterações ocorridas nas últimas décadas no mundo do trabalho têm legitimado o surgimento de políticas de reconhecimento de competências adquiridas em contextos informais e não formais. Em Portugal, o Sistema de Reconhecimento, Validação e Certificação de Competências (RVCC) foi colocado em prática em 2001, adoptando como suporte metodológico o balanço de competências e a abordagem autobiográfica. Neste artigo procuramos analisar o uso da autobiografia no contexto da educação de adultos baseada no reconhecimento de adquiridos experienciais. Olhamos com particular atenção o relato das experiências profissionais procurando identificar as estratégias narrativas que os candidatos utilizam na valorização de suas aprendizagens. Recorrendo a um corpus analítico de cem autobiografias, identificámos a existência de um conjunto de recursos narrativos usados pelos candidatos no relato autobiográfico que, em virtude da natureza do episódio profissional, procura conferir-lhes pertinência à luz do processo.

PALAVRAS-CHAVE

autobiografia; educação de adultos; narrativa; reconhecimento de competências. 


\title{
THE USE OF AUTOBIOGRAPHY IN ADULT EDUCATION: NARRATIVE MODES OF VALORIZATION AND LEGITIMATION OF PROFESSIONAL EXPERIENCE
}

\begin{abstract}
The changes in recent decades in the world of work have legitimized the emergence of policies of recognition of prior learning acquired in informal and non-formal contexts. In Portugal, the Recognition, Validation and Certification System (RVCC) was implemented in 2001, supported on the balance of skills and on the autobiographical approach. In this article we analyze the use of autobiography in the context of adult education based on the Accreditation of Prior Experiential Learning. We look with particular attention to the professional episodes trying to identify the narrative strategies that candidates use in valuing and legitimizing their learning. Using an analytical corpus of one hundred autobiographies, we have identified the existence of a set of narrative resources used by the candidates in the autobiography, due to the nature of the professional episode, in an attempt to ensure the pertinence of the process.

\section{KEYWORDS}

autobiography; adult education; narrative; recognition of prior learning.

\section{EL USO DE LA AUTOBIOGRAFÍA EN LA EDUCACIÓN DE ADULTOS: MODOS NARRATIVOS DE VALORACIÓN Y LEGITIMACIÓN DE LA EXPERIENCIA PROFESIONAL}

\section{RESUMEN}

Los cambios en las últimas décadas en el mundo del trabajo han legitimado el surgimiento de políticas de reconocimiento de competencias adquiridas en contextos informales y no formales. En Portugal, el sistema de Reconocimiento, Validación y Certificación de Competencias (RVCC) se implementó en el año 2001, mediante la adopción de un soporte metodológico del análisis de calificaciones y el enfoque autobiográfico. En este artículo se analiza el uso de la autobiografía en el contexto de la educación de adultos basado en el reconocimiento de la experiencia adquirida. Miramos con especial atención el relato de experiencias profesionales tratando de identificar las estrategias narrativas que los candidatos utilizan para valorar y legitimar su aprendizaje. Recurrimos a un corpus de análisis que consta de un conjunto de cien autobiografías y hemos identificado la existencia de un conjunto de recursos narrativas utilizadas por los candidatos en el relato autobiográfico.

autobiografía; educación de adultos; narrativa; reconocimiento de aprendizajes previos. 


\section{INTRODUÇÃO}

No relatório apresentado à Organização das Nações Unidas para a Educação, a Ciência e a Cultura (UNESCO) sobre a educação no século XXI, organizado por Jacques Delors em 1996, é recomendado o estudo de novas formas de certificação que tenham em conta o conjunto das competências adquiridas nos diferentes contextos de vida. $\mathrm{O}$ argumento vinculado no relatório é o de que, para promover uma sociedade em que cada um possa aprender ao longo de toda a sua vida, é necessário repensar as relações entre os sistemas de ensino e a sociedade, devendo ser dada particular atenção "a novas formas de certificação, a uma passagem mais fácil de um tipo ou de um nível de ensino para outro, e a separações menos estritas entre educação e trabalho"(Delors et al., 1996, p.123). No que diz respeito ao reconhecimento de competências, é atribuída particular importância às competências adquiridas durante a vida profissional e ao seu reconhecimento por parte das empresas e do sistema educativo. Subjaz, nesse relatório, uma imagem dos indivíduos como responsáveis por sua formação em "sociedades educativas" voltadas para os recursos da educação informal:

[...] a fim de que todos possam construir, de maneira contínua, as suas próprias qualificações, a Comissão pensa que é indispensável proceder [...] a um reexame profundo dos processos de certificação, a fim de que sejam tidas em conta as competências adquiridas após a educação inicial. (Delors et al., 1996, p. 148-149)

Em 2000, no Memorando sobre aprendizagem ao longo da vida, da responsabilidade da Comissão Europeia, são igualmente formulados apelos à modernização dos sistemas e das práticas de certificação dos Estados-membros perante as novas condições económicas e sociais. Entre as medidas propostas, encontra-se a melhoria significativa da forma como são entendidos e avaliados os resultados da aprendizagem, em especial a aprendizagem não formal e a aprendizagem informal. Os argumentos para a adoção de tais medidas incluem, por um lado, a crescente exigência de que "os conhecimentos, as competências e as qualificações sejam mais prontamente identificáveis e mais praticamente 'transportáveis' no seio da União [Europeia]" e, por outro lado, "o alargamento do espetro de reconhecimento, independentemente do tipo de aprendente em questão" (Comissão Europeia, 2000, p. 17-18).

A legitimação de novos espaços de aprendizagem, para além da escola, impeliu o surgimento de sistemas de certificação e equivalência escolares das aprendizagens ocorridas em contextos não formais. Dessa forma, a criação, em 2001, do Sistema de Reconhecimento, Validação e Certificação de Competências (RVCC) em Portugal veio constituir uma novidade no sistema educativo, revestindo-se de um caráter inovador na oferta dirigida a adultos pouco escolarizados. O pressuposto dessa oferta educativa assenta na existência de uma ligação entre o processo de aprendizagem e a experiência de vida, justificando-se, desse modo, a criação de processos de reconhecimento e validação das aprendizagens que ocorrem ao longo da vida e a consequente atribuição de um certificado de equivalência escolar. 
O sistema RVCC implementado em Portugal é orientado pelo Referencial de competências-chave, no qual estão elencadas as competências necessárias para a certificação. O processo baseia-se na elaboração e recolha de informação coligida em um documento, designado de Portefólio reflexivo de aprendizagens, com base em um conjunto de pressupostos metodológicos: o balanço de competências e a abordagem autobiográfica. É por meio dos materiais que o adulto produz, de forma contextualizada e crítica, que os formadores validam as competências por ele possuídas, para, em momento posterior, serem objeto de certificação. Assim, apesar de o processo se traduzir no reconhecimento de competências e saberes obtidos fora da lógica do sistema de aprendizagem formal, este depende, em última análise, da capacidade de descrever e relatar as experiências de vida do adulto. A descrição das atividades profissionais e da experiência de vida, sendo o principal dispositivo de validação, valoriza a componente escrita inerente ao processo e o aproxima do modelo escolar tradicional, que se baseia, de forma nuclear, na escrita. Verifica-se, portanto, que o processo RVCC incorpora disposições reflexivas, relacionadas com a escrita, que coincidem com a razão escolar (Lahire, 2008) valorizada pela escola.

Neste artigo, procuramos analisar o uso da autobiografia no contexto da educação de adultos baseada no reconhecimento de adquiridos experienciais. Olhamos, com particular atenção, as estratégias narrativas que os candidatos utilizam no relato da sua experiência profissional de modo que se possa valorizar e legitimar as suas aprendizagens.

\section{OPÇÕES METODOLÓGICAS}

Diante de nosso objetivo, recorremos à análise de um corpus documental constituído por cem autobiografias elaboradas por ex-candidatos do sistema RVCC que concluíram o processo entre 2006 e 2012 em quatro escolas da região Alentejo. Apesar de não ter existido preocupação de constituir uma amostra estatisticamente representativa de autobiografias, procurou-se, ainda assim, diversificar a amostra, ajustando-a, na medida do possível, ao perfil dos 1.400 candidatos certificados à data de setembro de 2012. Na Tabela 1 é apresentada a distribuição da amostra pelas diferentes variáveis de caracterização.

O material autobiográfico recolhido foi compilado e trabalhado de modo que pudesse ser sujeitado aos procedimentos de análise de conteúdo, seguindo a lógica inerente à análise qualitativa (Guerra, 2006), com o propósito de interpretar e reconstruir o sentido da narrativa, "produzindo as categorias e proposições (hipóteses explicativas) indispensáveis ao entendimento dos fenómenos através de um processo indutivo" (Guerra, 2006, p. 32). Subjaz ao trabalho analítico a ideia de que os conteúdos narrativos indiciam conteúdos culturais latentes que são mediados pelas estruturas sociais e simbólicas que contextualizam a sua produção (Ruquoy, 1997, p. 89). Em última instância, a nossa análise foi conduzida com a intenção de proceder à "inferência de conhecimentos relativos às condições de produção" (Bardin, 2009, p. 40).

Após a definição inicial de categorias de análise e da grelha analítica, procedemos à identificação, nos documentos autobiográficos, das unidades de registo 
categorizáveis e análogas entre si. As unidades de registo identificadas foram, sobretudo, de natureza semântica (baseadas em uma escolha resultante do sentido temático) e linguística (destacando-se, nesse nível, as palavras-chave) (Ghiglione e Matalon, 2001). Todo o material autobiográfico foi classificado com base nos critérios geralmente seguidos na análise de conteúdo (Bardin, 2009): a exaustividade (abrangendo a totalidade do material recolhido), a exclusividade (evitando classificar um mesmo elemento do conteúdo em duas categorias diferentes) e a pertinência (procurando classificar os trechos em razão dos objetivos da análise).

O material autobiográfico recolhido é extenso e marcado, em uma primeira leitura, pela singularidade de cada relato de vida. Somente após o trabalho de exploração e de leitura atenta se revelaram os traços comuns dos modos de aprendizagem em contextos informais. Os pontos comuns que surgem de forma recorrente em diferentes narrativas autobiográficas correspondem às marcas de saturação empírica que fornece uma base sólida à generalização das conclusões (Bertaux, 1997).

\section{A NARRATIVA AUTOBIOGRÁFICA NO PROCESSO DE RECONHECIMENTO DE ADQUIRIDOS EXPERIENCIAIS}

As narrativas autobiográficas analisadas assumem as mais diversas formas e estilos, diferindo no tipo de vocabulário, na construção frásica e na clareza do texto. No entanto, todas elas traduzem uma capacidade de objetivar e racionalizar

Tabela 1 - Caracterização da amostra

\begin{tabular}{|c|c|}
\hline & Número \\
\hline \multicolumn{2}{|l|}{ Sexo } \\
\hline Masculino & 45 \\
\hline Feminino & 55 \\
\hline \multicolumn{2}{|l|}{ Grupo etário (anos) } \\
\hline$>64$ & 5 \\
\hline Entre 55 e 64 & 10 \\
\hline Entre 45 e 54 & 35 \\
\hline Entre 35 e 44 & 30 \\
\hline Entre 25 e 34 & 18 \\
\hline$<25$ & 2 \\
\hline \multicolumn{2}{|l|}{ Habilitações literárias } \\
\hline $1^{\circ}$ ciclo (4 anos de educação formal) & 31 \\
\hline $2^{\circ}$ ciclo (6 anos de educação formal) & 60 \\
\hline $3^{o}$ ciclo (9 anos de educação formal) & 9 \\
\hline
\end{tabular}

Fonte: banco de dados da pesquisa.

Elaboração do autor. 
as experiências de vida, ordenando-as por meio de uma ordem cronológica e causal, hierarquizando as suas diversas partes.

O relato da experiência pessoal produz, necessariamente, leituras subjetivas, mais ou menos detalhadas, de diferentes episódios de vida tidos como relevantes no âmbito do processo RVCC. O trabalho de construção da narrativa autobiográfica envolve um duplo esforço: por um lado, a narração das contingências da vida, apresentadas de forma coerente com os objetivos do processo RVCC, e, por outro lado, a atribuição de linearidade à narrativa concebida como um itinerário.

A narrativa assume particular importância no processo RVCC, permitindo o acesso não apenas à sequência dos acontecimentos de vida, mas igualmente aos quadros de referência do candidato. Para Elliott (2005), a narrativa pode ser entendida como a organização de uma sequência de acontecimentos de tal forma que o significado de cada acontecimento seja entendido por meio da sua relação com o todo. No processo RVCC, a organização e a sequenciação da narrativa é fruto de um trabalho de seleção por parte do candidato, dos acontecimentos de vida que considera relevantes no decurso da realização de si próprio, pressuposto no processo.

O processo RVCC exige explicitamente ao candidato que narre a sua história de forma coerente e límpida, o que obriga a um trabalho de unificação identitária, quando raramente os indivíduos se encontram em situação de se dizer de uma forma contínua e desenvolvida (Kaufmann, 2005; Martuccelli, 2007). Essa intimidação do candidato em narrar-se enquadra-se naquilo a que Kaufmann (2005) designa de religião identitária da nossa época, ou seja, a conviç̧ão abstrata de que existe um "eu" à margem das contingências e dos contextos diversos que o reformulam: "esta convicção fluida, mas intensa, alimenta [...] a ideia de que uma narrativa das narrativas, forma de narração pura e fluida, está em todo o momento disponível” (Kaufmann, 2005, p. 136). Bastaria, portanto, invocar essa narrativa das narrativas para instituir sentido a sequências e episódios de vida, muitas vezes sem grande continuidade lógica entre si. O processo RVCC compele, assim, o candidato a encontrar um fio narrativo em percursos de vida que são marcados, com frequência, por experiências acidentais e, por vezes, incongruentes. Esse trabalho de unificação, encerrado na narrativa da história de si mesmo, favorece o surgimento da imagem do candidato como "autor" de sua própria vida.

Os instrumentos de mediação utilizados no processo RVCC apelam à narrativa biográfica com todas as suas características, sobressaindo, no entanto, duas particularidades. Em primeiro lugar, os instrumentos de mediação favorecem a definição, por parte do narrador, de uma unidade global e definitiva, responsável por expulsar incongruências e dissonâncias, pressupondo aquilo que Kaufmann designa de trabalho de "montagem incansável de carpinteiro das linhas da força da vida" (Kaufmann, 2005, p. 148). A identidade construída a partir da narrativa é dissemelhante à identidade imediata, construída em contextos precisos, carregados de concretude e inseparável da ação. A identidade narrativa resulta, pois, de um trabalho conduzido "em certos momentos particulares e privilegiados, um pouco à margem da ação habitual, em solidão, ou com cúmplices”(Kaufmann, 2005, p.148). No caso concreto do processo RVCC, a reflexão e a avaliação da experiência de vida, sendo um processo eminentemente individual, envolve também a participação 
"cúmplice" das equipas técnico-pedagógicas, cujo papel não é somenos importante, tendo em conta que visa:

criar uma dinâmica, um clima de confiança e de interajuda, que forneça feedback, valorizando iniciativas de mudança e de risco, que motive e estimule o "conceito de si enquanto aprendente" e o sentir-se "competente" para aprender. Isto significa [...] sublinhar a importância e o papel fundamental dos agentes profissionais das equipas técnico-pedagógicas de RVCC enquanto "tutores" neste processo de mediação, de mundos, culturas e experiências de aprendizagem tão distintas. (Gomes et al., 2006, p. 28)

A segunda característica da narrativa biográfica envolvida no processo RVCC consiste no facto de esta se estruturar na perceção ocidental de indivíduo, no sentido que lhe confere Martuccelli (2007), e que corresponde à imagem de um ator que passa de um estado inicial, informe, para um estado acabado, graças à realização de si. Nesse sentido, a narração de si, presente no portefólio do processo RVCC, recobre uma lógica de autoformação permanente. $\mathrm{Na}$ construção da narrativa, o candidato tem de necessariamente selecionar os acontecimentos de vida tidos por relevantes e coerentes com a imagem que quer projetar de si a quem avalia. $O$ relato que dita a unidade de si não é, assim, uma construção meramente solitária, é também fruto da influência cultural do contexto em que a história de vida é produzida. O processo RVCC não fica imune ao risco do fenómeno de folclorização identitária, identificado por Martuccelli (2007), e traduzido em um "embelezamento" de si à luz dos pressupostos do processo. O candidato é estimulado a narrar-se partindo do "conceito de si enquanto aprendente" e enquanto sujeito "competente para aprender".

\section{A DESCRIÇÃO DO PROCESSO DE APRENDIZAGEM EM CONTEXTO PROFISSIONAL}

A maioria dos episódios relatados na descrição de experiência profissional tende a centrar-se na forma como os canditados potenciaram a aprendizagem. Em seu discurso, é amplamente valorizada a dimensão pedagógica do trabalho, realçando aquilo que aprenderam no exercício de determinada profissão. Nesses relatos, as atribuições funcionais constituem um guia na enumeração das aprendizagens realizadas. A experiência é a base a partir da qual se produz o conhecimento.

Entretanto vou para Lisboa e vou trabalhar para o hospital [...], como auxiliar de ação médica, estava na secção de ortopedia feminina. Aprendi a colocar a arrastadeira, com pessoas com problemas na coluna, e a fazer uma cama do pós-operatório, pois a cama tem que estar adaptada, para facilitar a colocação do doente na cama após sair da maca do bloco operatório. Aprendi a alimentar um doente através da sonda, mudar um doente através do elevador hidráulico, utilizado para pessoas obesas. (Gregório, 45 anos) 
O discurso incorpora, invariavelmente, uma das principais premissas associadas ao processo RVCC: a de que os contextos profissionais constituem espaços de aprendizagem, nos quais os saberes se desenvolvem na ação. De facto, é na ação que se alicerça toda a argumentação que sustenta a demonstração das aprendizagens ocorridas no contexto profissional, e todos os episódios relatados revelam uma componente formativa que potencia aprendizagens. $\mathrm{O}$ trabalho implica a mobilização de competências, de conhecimentos e de capacidades, e é no relato do conteúdo funcional que se descrevem as aprendizagens e se insinuam as competências. Em todo caso, as aprendizagens, os conhecimentos e as competências são fortemente contextualizadas, vinculadas a situações concretas, afastando-se, portanto, quaisquer pretensões a um saber de natureza universal. A expressão dos saberes na narrativa procede-se, naturalmente, de modo retórico, circunscrevendo a formalização dos saberes nos diferentes domínios profissionais específicos, com recurso a códigos próprios, assim como à linguagem do quotidiano.

No entanto, nem todos os contextos profissionais são particularmente propícios ao desenvolvimento de competências escolares. Nessas situações, sobressai a forma cuidada com que os candidatos compõem a descrição das tarefas profissionais. Tarefas pouco complexas e aparentemente simples ganham dimensão particular no relato autobiográfico. Tomemos o exemplo de Felismina, com um percurso profissional marcado por diversas experiências profissionais. Entre o rol de profissões, incluem-se algumas cujo conteúdo funcional se reporta a atividades pouco ou mesmo não qualificadas, como empregada de andares, auxiliar de serviços gerais e ajudante de cozinheira. A forma como Felismina ornamenta seu discurso, ao explicar a tarefa de fazer uma cama, atribuindo-lhe maior importância e complexificação, constitui um bom exemplo.

O meu chefe era o sr. Fernando, boa pessoa, mas muito exigente. Aprendi a fazer camas de maneira diferente, com mais requinte, a acertar o vinco do lençol de baixo com o de cima e fazer os cantos em baixo tipo envelope. (Felismina, 47 anos)

Por meio desse exercício de realçar o que aprendeu de diferente, que se distingue do modo comum de realização de ações quotidianas, a candidata procura valorizar suas aprendizagens, conferindo-lhes valor e relevância para o processo. A maioria dos exemplos apresentados anteriormente inscreve o processo de aprendizagem na dimensão técnica da experiência profissional, embora se encontrem, igualmente, várias referências à dimensão relacional do processo de aprendizagem.

Para poder obter mais algum dinheiro extra, trabalhei também nos fins de semana em casamentos, batizados e outras festas para o restaurante [...] da minha prima Rosalina. Onde aprendi a apurar os meus dotes culinários com pessoas mais velhas e experientes, vi como se preparava um casamento, pois as pessoas que vão às festas muitas vezes não têm a noção do trabalho todo que está por detrás destes eventos. (Felismina, 47 anos) 
Ainda que, como se infere do excerto, Felismina fosse já detentora de "dotes culinários", foi no contexto profissional que estes foram "apurados", aprendendo com pessoas mais velhas e experientes. As referências à aprendizagem colaborativa com colegas mais experientes surgem com recorrência nas situações em que o acesso à profissão se faz sem requisitos de qualificação específica.

Eu consegui trabalho no Lar Nossa Senhora das [...], onde já trabalho há catorze anos. Ao longo destes anos já tive várias funções, tais como deitar e levantar idosos, fazer os curativos, fazer-lhes a higiene, limpezas, entre muitas coisas. Há um ano fui para a cozinha como ajudante e hoje trabalho como cozinheira. É um trabalho que gosto e onde sou bem tratada. [...] Nunca fiz formação em geriatria, tudo o que sei aprendi com as colegas de trabalho e sozinha. (Francisca, 46 anos)

Em muitos casos, nesses processos de aprendizagem é destacado e reconhecido o papel de referência de um superior hierárquico que orientou o candidato no processo de integração inicial.

[...] Em todas estas funções exercidas por mim, tive formação dada pelo meu chefe de turno, das quais não tenho certificados visto serem formações internas, pois trabalhava a turnos. O meu chefe era uma pessoa simpática, divertida e que gostava de ajudar e ensinar. Estive nesta fábrica durante seis anos. (Caetano, 35 anos)

O discurso dos candidatos procura legitimar os processos de aprendizagem, atribuindo-lhes um valor equivalente à formação formal. Tratando-se de processos de aprendizagem não formais e, simultaneamente, não estruturados, a inexistência de certificados e diplomas é lamentada, na medida em que correspondem à ausência de comprovativos das competências adquiridas.

Em algumas das ações de formação fazíamos simulacros de situações de risco para sabermos a forma de agir perante determinadas situações. Por vezes, são-nos dados os certificados da formação, no entanto nem sempre acontece. (Diana, 45 anos)

Os casos em que as aprendizagens ocorrem por intermédio dos processos formativos que conduzem à atribuição de certificados e de diplomas constituem episódios narrados com particular destaque na autobiografia. Nessas situações, o processo de argumentação é facilitado pela existência de um programa de formação, que permite objetivar as aprendizagens, bem como pela existência de uma nota final, que permite objetivar o resultado das aprendizagens. A formação certificada constitui, assim, o modo privilegiado de produção de prova do processo de aprendizagem no contexto profissional e os seus resultados constituem elementos, por excelência, de demonstração do valor individual. Quando presentes, assumem uma dimensão importante da narrativa da experiência profissional, quer no tocante à enumeração exaustiva de certificados ou a relato de aprendizagens. 
Este curso decorreu entre fevereiro de 1999 e junho de 1999, no qual tive catorze valores. Era dado por vários formadores durante cerca de duas horas semanais, aos sábados e domingos. Neste curso aprendi várias coisas sobre os idosos, para the proporcionar uma melhor qualidade de vida; por exemplo, aprendemos qual a melhor forma para colocar os idosos, sem que ficassem com feridas, após estarem acamados. Tínhamos que fazer fichas de trabalho e consoante o resultado desses trabalhos era dada uma nota. [...] Vimos neste curso a institucionalização dos idosos, tem de existir obrigatoriamente uma passagem do informal para o formal. Começamos por falar no envelhecimento e velhice e a definição de envelhecimento e definição da velhice, onde identificamos os fatores relacionados com o envelhecimento. No módulo da "Autonomia: a definição de independência e dependência”, aprendeu-se a relação entre autonomia e a independência [...]. (Xénia, 50 anos)

A classificação final é um aspeto importante e fortemente valorizado na narrativa dos candidatos, na medida em que constitui uma prova do seu valor no processo de aprendizagem. Acresce à nota a existência de um certificado, que constitui um importante elemento na documentação apresentada no processo RVCC e cuja valorização se pode constatar pela forma como tal documento é anexado à autobiografia.

O presente Portefólio Reflexivo de Aprendizagens é constituído pela minha apresentação, carta de apresentação e curriculum, seguido da minha história de vida e de todos os anexos que comprovam as formações que fui adquirindo ao longo do meu percurso de vida. (Telma, 53 anos)

No corpus de cem autobiografias que constituiu a base de análise deste trabalho, podemos identificar um elevado número de candidatos (57\%) que refere ter frequentado formação certificada relacionada com a sua profissão. Ainda assim, são muito diversas as configurações dos modelos de formação, que variam entre pequenas ações de formação pontuais até cursos de formação profissional ministrados por instituições oficiais.

A maioria dos cursos de formação referidos pelos candidatos diz respeito a ações de formação que ocorrem no início do exercício de determinada função profissional.

Fiquei muito contente por ter conseguido este emprego, pois era isto que eu gostava de fazer, cuidar de doentes e pessoas idosas. Quando entrei, comecei por fazer um curso de geriatria e tive várias ações de formação. Aprendi coisas espetaculares, como medir a tensão arterial, fazer o teste de BM, glicemias, dar insulina, administrar medicação e muitas outras coisas que para mim foram uma mais-valia para poder ajudar aqueles que mais necessitam. (Bárbara, 40 anos) 


\section{MODOS NARRATIVOS DE VALORIZAÇÃO E LEGITIMAÇÃO DA EXPERIÊNCIA PROFISSIONAL}

Evidencia-se, pela leitura do material autobiográfico, a existência de diferentes estratégias discursivas e modos de produção narrativa utilizados pelos candidatos em virtude da natureza do episódio ou da experiência profissional relatada e da imagem de si que pretendem projetar. Os diferentes recursos a que nos referimos constituem modos de dar forma à narrativa, consoante a maior ou menor pertinência do episódio relatado, diante dos objetivos do processo RVCC. Nesse sentido, consideramos que a apresentação de episódios profissionais ao longo da narrativa tende a ser moldada por cinco modos diferentes de legitimação narrativa da experiência profissional à luz do processo RVCC, a saber:

1. Descrições detalhadas e desenvolvidas que realçam a posse de competências técnicas ou a vocação para o exercício da atividade profissional;

2. Relatos que procuram impressionar o leitor com base na descrição dos aspetos inusitados e, à partida, desconhecidos do leitor, relativos a atividades profissionais específicas;

3. Descrições que valorizam episódios profissionais com base em sua dureza, bem como no esforço associado à sua realização;

4. Relatos de episódios que glorificam o percurso profissional;

5. Descrições parcelares e fragmentadas da experiência profissional.

\section{DESCRIÇÕES DETALHADAS QUE REALÇAM A POSSE DE COMPETÊNCIAS}

O primeiro modo narrativo da experiência profissional consiste na descrição das responsabilidades funcionais de forma detalhada e elaborada. Essa estratégia de composição narrativa procura debelar a eventual banalidade que o leitor atribua às tarefas profissionais do candidato. O processo de preparação da carne para comercialização no açougue, por exemplo, é descrito com alguma minúcia.

[...] já tinha alguma prática e sabia algumas técnicas de cortar, como, por exemplo, para cortar bife, calça-se uma luva de aço na mão esquerda, se não for esquerdino, é indispensável, faz parte da segurança no trabalho, depois pousa-se a mão esquerda por cima da peça que se vai cortar e com a faca na mão direita, cortam-se os bifes. Também tinha começado a aprender a desossar peças grandes; todas têm um veio onde se começa, tem é que conhecer-se as peças. As mais pequenas, galinhas, porcos, borrego, coelho, etc., são pelo encaixe [...]. (Olga, 40 anos)

A enumeração exaustiva de conhecimentos adquiridos por meio das diferentes experiências profissionais, assim como o destaque dado aos conhecimentos técnicos exigidos para a realização das tarefas, constitui outro exemplo. 
Quando fui para [...] trabalhar no concessionário da [...], assumi este trabalho com muita responsabilidade. As minhas funções consistiam na reparação de travões, que se verifica quando existe uma fuga na parte hidráulica dos travões, tinha que substituir os tubos do travão que estavam danificados, ou seja, com fuga; mudar as pastilhas dos travões quando estas estavam gastas; mudar o óleo, amortecedores, afinar os faróis; mudar o disco de embraiagem; reparava também avarias, como na cisterna de refrigeração, onde temos que conhecer o circuito, que é constituído por tubos onde passa a água, válvulas elétricas de temperatura, termóstato, radiador, electro-ventilador e bomba de água. [...] Em suma, este trabalho proporcionou-me conhecimentos específicos de mecânica, que ainda hoje em dia me são úteis, uma vez que sou eu que faço a revisão à minha carrinha. (Guilherme, 42 anos)

Também a enumeração de realizações profissionais permite demonstrar a detenção de aptidão para o exercício de determinada profissão.

Quando trabalhei por minha conta, Deus deu-me a felicidade de conseguir eu próprio fazer máquinas para trabalhar o ferro e aço; inventei a máquina de retalhar azeitonas e de pisar as mesmas. Mais tarde, em 1994, fiz a máquina mais cara que tenho na minha oficina, uma máquina de quinar chapas, com várias toneladas de ferro a aço, através do catálogo que me mandaram do Porto, sem nunca ter visto uma igual. (Quintino, 50 anos)

A argumentação tende a centrar-se na especificidade das competências especializadas obtidas, quer pela formação de base, quer pelo saber-fazer adquirido com a prática. O reconhecimento é procurado por via da demonstração do envolvimento profissional que, em alguns caos, é intensificado pela mobilização da conceção de vocação inerente ao discurso.

Dois anos depois, fui convidada para tomar a responsabilidade da despensa e de todas as aquisições, incluindo a alimentação e as ementas. Todas as segundas-feiras tinha que apresentar a ementa para toda a semana, o que sempre fiz sem qualquer problema. Sempre que algum dos miúdos fazia anos, tinha a oportunidade de escolher a refeição, assim como a sobremesa e o bolo, que a maioria das vezes era eu que o fazia e decorava ao gosto deles e deliciava-me a fazer-lhes estes mimos, que para eles tanto representavam, sendo que para alguns era o primeiro bolo de aniversário que tinham. [...] Reconheço que ao longo destes vinte e três anos tenho dado muito de mim, pois uma instituição onde vivem crianças e jovens com estas características assim o exige, mas também tenho sido bastante recompensada pelos seus sorrisos, abraços, lágrimas e todas as manifestações de carinho que estes jovens sabem dar, muitos foram aqueles que conheci e que me marcaram pela sua história de vida, pelo seu sofrimento, pela sua forma de encarar a vida e outros pelo seu grande coração e pelo seu sucesso. (Emília, 68 anos) 
A dedicação recompensada com bens imateriais faz de sua atividade mais que uma profissão, uma vocação. É possível observar, nas palavras da candidata, o exercício de uma profissão com uma configuração próxima do contexto doméstico. Esse aspeto expressa-se na forma como lida com as crianças, valorizando os laços de afetividade e devoção próprios da maternidade. A sua profissão é entendida como uma missão, com o objetivo de resgatar as crianças do sofrimento e orientá-las para o sucesso.

\section{RELATOS QUE PROCURAM IMPRESSIONAR O LEITOR}

O segundo modo narrativo consiste no relato da experiência profissional recorrendo a descrições, desenvolvidas e detalhadas, que procuram revelar aquilo que no processo produtivo é, à partida, desconhecido da equipa técnica envolvida no processo RVCC. Nesses casos, em simultâneo com a descrição das responsabilidades profissionais, alguns candidatos assumem o papel de guia que orienta o leitor no acesso ao lado obscuro do processo produtivo. Nessas situações, é reforçada a demarcação da experiência profissional descrita relativamente a outras experiências mais banais, levando à inclusão de aspetos inusitados na argumentação. Procura-se o reconhecimento por meio da tentativa de impressionar o leitor, destacando-se a importância social de um trabalho que se demarca pela sua invulgaridade, mas que é necessário ser realizado. $\mathrm{O}$ exemplo mais paradigmático dessa estratégia encontramo-lo na descrição que Ismael faz de uma das suas experiências profissionais, a construção de urnas funerárias.

As urnas, no primeiro ano que lá trabalhei, ainda eram feitas de madeira de pinho. Depois entrou no mercado o MDF, que é uma madeira prensada, melhor de trabalhar e mais barata. Também era eu que fazia a distribuição das urnas por várias agências funerárias, por quase todo o país. Além disto, quando alguém falecia no hospital ou noutro sítio qualquer, era eu que ia com o carro funerário levar a urna para o defunto, desde que o funeral fosse entregue ao meu patrão. Éramos onze empregados, cinco homens e seis mulheres. Por dia, tínhamos que fazer onze urnas, pois o patrão queria uma urna por cada funcionário. Estas eram classificadas por números, tínhamos seis números ou seis modelos; quanto mais baixo fosse o número, mais barato eram as urnas. Tínhamos ainda outros dois modelos diferentes destes, a de cremação e de mogno, que são as que se colocam para os jazigos. A urna de cremação é praticamente igual às outras, a única diferença é que não pode levar metais no seu fabrico, como, por exemplo, pregos ou agrafos. A urna de mogno já é feita de uma madeira exótica e dura vários anos, no mesmo estado de conservação, pois não vai para a terra, fica apenas em jazigos, o que a torna mais cara. Entre fazer caixões funerários ou móveis, gostei mais de fazer os primeiros, já que considero um trabalho de alguma coragem. Normalmente, as pessoas associam logo urna com morte. Para mim, foi um trabalho igual a outro qualquer, já que alguém tinha que o fazer, para mim tornar-se-ia mais difícil se a urna aparecesse logo feita. 
Como isso nunca aconteceu, nunca tive esse problema, eram todas feitas lá, desde o princípio até ao fim. Foi uma boa experiência e um grande desafio para mim. (Ismael, 40 anos)

\section{DESCRIÇÕES QUE VALORIZAM EPISÓDIOS PROFISSIONAIS COM BASE NA SUA DUREZA}

O terceiro modo narrativo é particularmente visível nas situações potencialmente problemáticas no âmbito do processo RVCC, em que a experiência profissional que se retrata diz respeito a trabalhos pouco qualificados e qualificantes e que, por isso, conferem poucas oportunidades de evidenciação de competências envolvidas no processo. Nessas situações, a dificuldade de centrar a narrativa no domínio de competências desloca a argumentação para o domínio das dificuldades inerentes à realização das tarefas. Assim, a valorização da experiência profissional passa pelo realce da dureza do trabalho, das adversidades enfrentadas e do esforço envolvido na sua realização.

Embora fosse um trabalho difícil, principalmente a apanha da azeitona, já que era de inverno de manhã e estava muito frio, as mãos acabavam por ficar geladas porque a azeitona e as oliveiras estavam cheias de gelo. Fazíamos lume, mas depois era pior, pois quando as mãos começavam a aquecer começavam também a doer e lá tínhamos que ir apanhar outra vez a azeitona. (Laura, 53 anos)

A generalidade das experiências profissionais de natureza menos qualificada enquadra-se no trabalho agrícola. A natureza de muitas das tarefas agrícolas descritas, de execução pouco complexa e de baixo nível de exigência de mobilização de competências passíveis de certificação escolar, poderia, à partida, colocar em causa a sua pertinência no âmbito do processo RVCC. Nesses casos, a penosidade do trabalho ganha particular relevo na narrativa, salientando-se o facto de ser um trabalho para o qual nem todos estão talhados, em razão, especialmente, à exigência física. O trabalho agrícola realizado no período do inverno, em condições particularmente adversas, é, dessa forma, narrado com maior detalhe.

Este era um trabalho no qual se ganhava bem, mas era muito duro, pois era e é feito no inverno, sob frio, chuva e vento. [...] Só recebíamos quando terminávamos de colher a azeitona toda, sabia bem receber aquele dinheiro todo junto. [...] Algumas pessoas desistiam antes do final da colheita devido à dureza do trabalho. Para colhermos a azeitona, tínhamos que bater a oliveira com um pau, para fazer cair a azeitona nos panos. Claro que tínhamos que bater com cuidado para não danificarmos a árvore. No final do dia ficava com bolhas nas mãos, chegando mesmo a fazer feridas de tanto andar com o pau. [...] Tudo isto requeria um grande esforço físico, pois todo este trabalho tinha que ser feito pelo casal. Seguindo depois para o lagar. (Helena, 41 anos) 
O relato das experiências profissionais menos qualificadas tende, assim, a dignificá-las, não pela sua complexidade técnica e consequentes exigências de competências, mas pela sua dureza. É a penosidade, que nem todos suportam, que valoriza essas experiências e as legitima como pertinentes para o processo de reconhecimento.

\section{RELATOS DE EPISÓDIOS QUE GLORIFICAM O PERCURSO PROFISSIONAL}

O quarto modo de apresentação da experiência profissional na narrativa autobiográfica consiste na evocação de episódios que glorificam o percurso profissional. Os sucessos e vitórias profissionais, em particular aqueles em que se destaca a importância do papel do candidato no domínio do processo de trabalho, ganham, aqui, grande destaque na narrativa.

Neste emprego houve uma vez em que uma equipa de investidores foi filmar uma nova peça da aeronave, que é feita em cortiça e eu era especializado em fazê-la. Nesse dia, foi-me entregue o cargo de liderar a equipe e ao mesmo tempo era o responsável pelo que pudesse acontecer. Assumi os riscos, mesmo estando um pouco instável, mas no final acabara tudo por correr bem. (Lourenço, 23 anos)

As progressões e promoções na carreira, a qualificação e, em alguns casos, os prémios de carreira constituem provas de competência e do reconhecimento por parte das chefias.

No ano de 1997, também tive um prémio pelos meus quinze anos de serviço, do qual muito me orgulho [...] Ter recebido este prémio foi uma recompensa tanto a nível profissional como pessoal. Senti que tinha cumprido as normas profissionais da instituição, com dedicação e eficiência. Consegui ultrapassar os meus objetivos e subir na carreira profissional. (Berta, 54 anos)

Igualmente, as situações em que ocorre a responsabilização do candidato pela formação de colegas com menos experiência profissional consubstanciam-se em oportunidades de demonstração do valor individual na narrativa autobiográfica.

Dava formação aos novos operadores, tarefa da qual muito gostava, lidava com todo o tipo de feitios e maneiras de ser, tinha toda a responsabilidade e era avaliado de seis em seis meses. Com estas avaliações, passei a especialista químico, o que muito me marcou porque me permitiu passar por duas categorias: operador semiespecializado e especialista, que eram o máximo. Ganhei o que ambicionara para brilhar nesta empresa, aqui trabalhava com temperaturas, stocks, planos de produção e mapas de competências. (Cesário, 32 anos) 
Os exemplos apresentados constituem manifestações de autovalorização do desempenho profissional e procuram revelar a detenção de capacidades que são valorizadas e reconhecidas pelos superiores hierárquicos.

\section{DESCRIÇÕES PARCELARES E FRAGMENTADAS DA EXPERIENNCIA PROFISSIONAL}

Por fim, o quinto modo narrativo de episódios de vida profissional corresponde a relatos com informação parcelar e fragmentada. Esses casos surgem normalmente associados, na autobiografia, a situações particularmente críticas relativamente à imagem pessoal que se pretende projetar. Tomemos como exemplo o relato de Ismael, a que nos reportámos anteriormente como ilustrativo da forma detalhada com que apresentou os seus conhecimentos na construção de urnas mortuárias. Outra de suas várias experiências profissionais consistiu no desempenho de funções em uma fábrica de preparação e transformação de cortiça, onde terá passado por diferentes secções do processo produtivo. $\mathrm{O}$ discurso do candidato permite-nos inferir que a adaptação ao posto de trabalho nem sempre foi fácil. A operação de traçamento da cortiça, que envolve o domínio de técnicas específicas de manuseamento da matéria-prima, bem como o manuseamento de equipamentos de traçar constituem exemplos de tarefas profissionais em que, como refere o próprio, houve dificuldades de adaptação.

$\mathrm{Na}$ fábrica, transformava-se a matéria-prima em rolhas, palmilhas e triturado. $\mathrm{Eu}$, quando fui para a fábrica, o meu trabalho consistia em descarregar os camiões que chegavam do mato com cortiça. Depois fui aprender a traçar cortiça, só que não me adaptei a esse trabalho e então mandaram-me para a trituração. (Ismael, 40 anos)

A escassez de detalhe do discurso de Ismael no relato da experiência da passagem pelo setor do traçamento de cortiça contrasta com a riqueza do discurso na referência a outras experiências profissionais mais favoráveis à imagem de si que pretende transmitir.

\section{CONCLUSÃO}

A utilização de abordagens autobiográficas na educação e formação de adultos corresponde a uma alteração da conceção de educação que deixa de se restringir à mera transmissão de conteúdos no contexto escolar e se alarga à compreensão dos vários contextos de vida dos sujeitos. A experiência constitui o recurso-base a partir do qual se realiza todo o processo de certificação escolar.

A prática educativa baseada nas abordagens autobiográficas objetiva a valorização da aprendizagem dos sujeitos ao longo da sua vida e nos mais variados contextos. Com base na análise realizada a um corpus analítico de cem autobiografias, foi possível identificar um conjunto de recursos narrativos usados pelos candidatos no relato autobiográfico e que, em virtude da natureza do episódio profissional, procura 
conferir-lhe pertinência à luz do processo RVCC. A narrativa autobiográfica, nesse contexto, é estruturada com base na imagem de um protagonista que se autoconstrói e se realiza pelo trabalho, passando de um estado inicial informe para um estado acabado, competente. $\mathrm{Na}$ construção da narrativa, o adulto seleciona e valoriza os acontecimentos de vida tidos por relevantes e coerentes com a imagem que quer projetar de si a quem avalia. As estratégias e os recursos narrativos, identificados nesta investigação, sustentam a construção do "eu" autobiográfico, uno, coerente, e ajustado aos pressupostos do processo RVCC. A narrativa autobiográfica produzida no processo RVCC não fica, assim, imune ao risco do fenómeno de "folclorização" identitária, identificado por Martuccelli (2007), traduzido em um "embelezamento" de si à luz dos pressupostos do processo.

A valorização dos episódios descritos, com base em estratégias discursivas que configuram a narrativa, é reveladora do processo de produção da narrativa autobiográfica como um ato social enquadrado em um contexto específico que condiciona a sua organização. Toda a narrativa se orienta para a legitimação do percurso profissional passível de ser reconhecido como um percurso propício à aprendizagem.

Nessa perspetiva, o processo de reconhecimento de competências é, em última instância, um dispositivo social de expressão individual e de apresentação a outros, valendo-se do relato autobiográfico, no qual se procura transmitir impressões a respeito de si próprio. Nesse processo, os atores sociais orientam a sua ação para a concretização de um objetivo concreto, a validação e a certificação de competências. A produção da narrativa autobiográfica é, assim, enredada por duas linhas que a condicionam: o enquadramento em uma oferta educativa destinada a adultos com requisitos de aferição de sucesso e a necessidade de a narrativa ser aceite e reconhecida por parte de uma audiência que a avalia.

O processo de narração autobiográfica no âmbito da educação de adultos assume contornos específicos. Se, por um lado, se reconhece à reflexividade do processo de escrita um potencial de aprendizagem, por outro lado, na medida em que o processo decorre em contexto educativo e sujeito a avaliação, os autores das narrativas recorrem a modos narrativos que deliberadamente contribuem para um embelezamento de si.

Os resultados obtidos realçam alguns limites às potencialidades da utilização da escrita de narrativas autobiográficas em contexto educativo. Ainda que se reconheça que a prática de escrita na primeira pessoa constitui um importante instrumento na educação de adultos, parece prudente que, na análise de narrativas, se tomem em consideração os processos de construção do discurso que sustenta a imagem de si. Tais cuidados resultam do facto de a realização dialógica, implícita na prática de escrita de si em contexto educativo, não ser uma mera abertura e exposição de quem escreve ao seu leitor, ela é mais do que isso, é um processo de apresentação de si ao outro. Assim, como podemos constatar na análise de relatos da experiência profissional, evidenciam-se, em tais narrativas, vários modos narrativos de valorização da experiência pessoal, que constituem importantes dispositivos de segurança do narrador na produção de uma imagem de si digna de reconhecimento aos olhos do seu leitor. 


\section{REFERÊNCIAS}

Bardin, L. Análise de conteúdo. Lisboa: Edições 70, 2009.

Bertaux, D. Les recits de vie: perspective ethnosociologique. Paris: Natham, 1997.

Comissão Europeia. Memorando sobre aprendizagem ao longo da vida. Bruxelas: Comissão Europeia, 2000. Disponível em: < http://dne.cnedu.pt/dmdocuments/Memorando\%20 sobre\%20Aprendizagem\%20Longo\%20da\%20Vida\%20pt.pdf >. Acesso em: 16 set. 2017. Delors, J.et al. (Org.). Educação: um tesouro a descobrir. Relatório para a UNESCO da Comissão Internacional sobre Educação para o século XXI. Brasília: UNESCO, 1996. Ghiglione, R.; Matalon, B. O inquérito. Lisboa: Celta Editora, 2001.

Gomes, M. et al. Referencial de competências-chave para a educação e formação de adultos nível secundário. Lisboa: Direç̧ão-Geral de Formação Vocacional, 2006.

Guerra, I. Pesquisa qualitativa e análise de conteúdo: sentidos e formas de uso, Lisboa: Principia, 2006.

ElLiott, J. Using narrative in social research. Londres: Sage, 2005.

Kaufmann,J. A invenção de si: uma teoria da identidade. Lisboa: Instituto Piaget, 2005.

LAHIRE, B. La raison scolaire. École et pratiques d'écriture, entre savoir et pouvoir. Rennes: Presses Universitaires de Rennes, 2008.

Martuccelli, D. Gramáticas del individuo. Buenos Aires: Losada, 2007.

RuQuoy, D. Situação de entrevista e estratégia do entrevistador. In: Albarello, L.; Almeida, J.; Baptista, L. Práticas e métodos de investigação em ciências sociais. Lisboa: Gradiva, 1997. p. 84-116.

\section{SOBRE O AUTOR}

António Calha é doutor em sociologia pela Universidade de Lisboa (Portugal). Professor do Instituto Politécnico de Portalegre (Portugal). E-mail: antoniocalha@hotmail.com 